\title{
Colette Trout et Derk Visser, Jean Giono
}

Sara Arena

\section{(2) OpenEdition}

\section{Journals}

\section{Edizione digitale}

URL: http://journals.openedition.org/studifrancesi/9027

DOI: 10.4000/studifrancesi.9027

ISSN: 2421-5856

\section{Editore}

Rosenberg \& Sellier

\section{Edizione cartacea}

Data di pubblicazione: 1 octobre 2008

Paginazione: 488-489

ISSN: 0039-2944

\section{Notizia bibliografica digitale}

Sara Arena, «Colette Trout et Derk Visser, Jean Giono», Studi Francesi [Online], 155 (LII | II) | 2008, online dal 30 novembre 2015, consultato il 11 janvier 2021. URL: http://journals.openedition.org/ studifrancesi/9027 ; DOI: https://doi.org/10.4000/studifrancesi.9027

Questo documento è stato generato automaticamente il 11 janvier 2021.

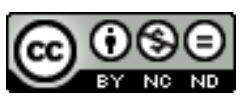

Studi Francesi è distribuita con Licenza Creative Commons Attribuzione - Non commerciale - Non opere derivate 4.0 Internazionale. 


\title{
Colette Trout et Derk Visser, Jean Giono
}

\author{
Sara Arena
}

\section{NOTIZIA}

COLETTE TROUT et DERK VISSER, Jean Giono, Amsterdam-New York, Rodopi, 2006 («Collection monographique Rodopi en littérature française contemporaine», 44), pp. 156.

1 Coerentemente con l'impianto della collana «Collection Monographique», la monografia di Colette Trout e Derk Visser si propone di offrire al lettore una presentazione al tempo stesso sintetica e analitica dell'opera di Jean Giono, considerata nelle varie fasi del suo percorso e della sua evoluzione. Senza rinunciare a proporre alcune interpretazioni e valutazioni originali, il saggio è ricco di rimandi all'état des lieux degli studi e della critica più recente sull'opera di Giono (con particolare riferimento agli apparati delle CEuvres romanesques complètes della «Pléiade»), per i quali costituisce - almeno per quanto concerne le questioni approfondite dagli autori - anche un valido quadro riepilogativo.

2 Nel capitolo di apertura, Giono et ses vies, Colette Trout e Derk Visser ripercorrono la biografia dello scrittore soffermandosi sugli aspetti più intimamente legati all'opera $\mathrm{e}$ analizzando in particolare la costruzione, da parte dello stesso Giono, di alcuni "miti" personali, come quello della povertà della famiglia d'origine e della formazione da autodidatta. Il capitolo successivo, La recherche de l'être complet, è incentrato sulla ricerca, nell'opera di Giono, di una nuova armonia tra uomo e natura, alla luce delle idee dell'autore sulle conseguenze negative della rivoluzione industriale e della civiltà capitalista nel rapporto tra individuo e ambiente.

3 Sempre sul crinale che mette in relazione le vicende biografiche con i temi della produzione narrativa, il capitolo Amitié/fraternité studia la rappresentazione dei legami di amicizia nei romanzi di Giono (rapporti di amicizia di varia natura: fraterna, unilaterale, frammista a componenti amorose...), istituendo alcuni possibili legami con 
le relazioni affettive della vita reale dell'autore. Quello successivo, Visages du féminin, prende in esame le numerose e complesse figure femminili della sua opera, analizzando anche le componenti sensuali - più o meno esplicite - che spesso le caratterizzano e le frequenti associazioni tra la femminilità e il campo semantico degli odori, della terra e della maternità.

4 La tesi di fondo del volume, resa ancor più esplicita nell'ultimo capitolo ed essenzialmente consonante con le conclusioni dell'équipe «Pléiade», risiede nella fondamentale unità dell'opera di Giono, a dispetto dell'usuale partizione in due "maniere", una precedente e l'altra successiva agli anni della Seconda guerra mondiale. Il capitolo conclusivo, L'art de Giono, è consacrato in quest'ottica allo studio di quelle caratteristiche che appaiono stabili nel tempo e profondamente ancorate nella sua scrittura, come la sua vocazione di conteur e la marca di racconto "orale" che contraddistingue molti dei suoi testi. 